\title{
Magnitude of Mental Illness and Associated Factors among Holy Water Users at Entoto St. Mary Church, Addis Ababa, Ethiopia, 2014
}

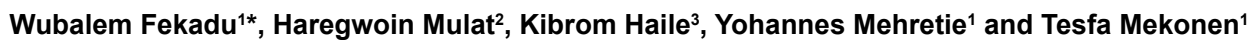

${ }^{1}$ College of Health sciences and Medicine, Wolaita Sodo University, Ethiopia

${ }^{2} P$ sychiatry Department, University of Gondar, Ethiopia

${ }^{3}$ Amanuel Mental Specialized Hospital, Addis Ababa, Ethiopia

\begin{abstract}
Introduction: Mental disorders are among the major causes of impairment which results in serious economical, social and other consequences. Many people with this disorder get religious help before or after getting modern treatment. Despite this there is lack of information which indicates the magnitude of mental illness among holy water users and associated factors.
\end{abstract}

Objective: The aim of the study was to assess the prevalence and associated factors of mental illness among holy water users at Entoto St. Mary Church, Addis Ababa, Ethiopia, 2014.

Method: Cross sectional study design was conducted from April 28-May 28, 2014 at Entoto St. Mary church A total of 416 holy water users were included in the study. The participants were selected using systematic random sampling method. Data were collected by face-to-face interviews using structured questionnaire for socio demographic factors, substance related factors using WHO's ASSIST, interview and observation by Brief Psychiatric Rating Scale (BPRS) for mental illness symptoms and clinical factors were collected using structured questionnaires.

Result: A total of 416 participants were interviewed and observed with a response rate of $98.35 \%$. The prevalence of mental illness was $60.1 \%$ with $95 \% \mathrm{Cl}$, $(54.34,65.86)$. Being jobless [AOR=2.42, $95 \% \mathrm{Cl}(1.37,4.28)]$, ever use of more than one substance (i.e. alcohol, tobacco, khat and cannabis) [AOR=2.4, 95\% $\mathrm{Cl}(1.39,4.17)]$, current daily drinking of alcohol $[\mathrm{AOR}=5.08,95 \% \mathrm{Cl}(2.08,12.2)]$, having previous history of mental illness $[\mathrm{AOR}=5.82,95 \% \mathrm{Cl}$ $(2.732,12.378)]$ and having a known medical or surgical problem $[A O R=2.46,95 \% \mathrm{Cl}(1.39,4.34)]$ were significantly associated with mental illness.

Conclusion: More than half of holy water users had mental illness so it needs to give attention to develop reference link between psychiatric institutions and religious places, people's awareness about the cause, consequence and treatment options of mental illness must be enhanced.

Keywords: Magnitude; Factors; Mental illness; Holy water users; Ethiopia

\section{Introduction}

Mental disorder is a clinically significant behavioral or psychological syndrome or pattern that occurs in an individual and that is associated with present distress (e.g., a painful symptom) or disability (i.e. impairment in one or more important areas of functioning) or with a significantly increased risk of suffering death, pain, disability, or an important loss of freedom [1]. About 450 million people suffer from mental and behavioral disorders worldwide. One person in four will develop one or more of these disorders during their lifetime [2]. Prospective studies indicate that the life time prevalence of mental illness reaches up to 38\% [3]. World Health Organization (WHO)'s World Mental Health (WMH) Survey result shows that life time prevalence mental illness varies from $7.4 \%$ in the United States to $12.0 \%$ in Nigeria $[4,5]$. In United States approximately about $26 \%$ of persons aged 18 years and older suffer from a mental disorder, in a given year almost 58 million people, in 2004 about $6 \%$ of adults or almost one in every four persons suffering from a mental disorder over the course of a year [6].

A national survey in USA to detect life time prevalence of mental illness by using World Health Organization World Mental Health Survey version of the Composite International Diagnostic Interview (WHO_CIDI) indicates that about $46.4 \%$ of individuals will develop one disorder in their life time [7] and other studies in LatinoAmericans reports life time prevalence as $28.1 \%$ for men and $30.2 \%$ for women and the factors associated was gender, substance use in both studies [8]. A study in South Africa by using WHO_CIDI indicate that approximately $32 \%$ of adults have experienced a DSM-IV disorder in their lifetime; of them $62 \%$ reported no treatment in the past 12 months and factors significantly associate were level of education and place of residence [9].

Another study in disadvantaged and rural communities of South Africa among three groups of the community (i.e. from the general population, primary care institutions and places of traditional healers) indicates that common mental illness was more prevalent in primary care institutions and traditional healers than general population (i.e. $34.9 \%, 72.5$ and $82.9 \%$ respectively). The factors associated were being female and unemployed [10]. In Ghana around 14\% of mentally ill individuals consult pastors and $5.9 \%$ receive consult from traditional healers and the main factors to alter place of help seeking are; area

*Corresponding author: Wubalem Fekadu, College of Health sciences and Medicine, Wolaita Sodo University, Ethiopia, Tel: +251912640423; E-mail: wubfek@gmail.com

Received March 10, 2015; Accepted April 21, 2015; Published April 28, 2015

Citation: Fekadu W, Mulat H, Haile K, Mehretie Y, Mekonen T (2015) Magnitude of Mental Illness and Associated Factors among Holy Water Users at Entoto St. Mary Church, Addis Ababa, Ethiopia, 2014. J Psychiatry 18: 285 doi: 10.4172/2378-5756.1000285

Copyright: (c) 2015 Fekadu W, et al. This is an open-access article distributed under the terms of the Creative Commons Attribution License, which permits unrestricted use, distribution, and reproduction in any medium, provided the original author and source are credited 
of residence, ethnicity, migration status, and prior use of medical services [11]. In Uganda help for mental illness is mostly sought from traditional healers initially, whereas modern care is usually considered as a last resort. The factors found to influence help seeking behaviour include: beliefs about the causes of mental illness, the nature of service delivery, accessibility and cost, stigma [12]. A rapid assessment of mental illness in Burundi, Democratic Republic of Congo and South Sudan indicates that most respondents think that the causes of mental illness are supernatural, psychosocial and natural. Non psychotic mental disorders are not regarded as a 'medical' disorder, and were therefore also not seen as a condition for which help should be sought within health institutions. Rather, help is expected from relatives to improve through social and emotional support, traditional healers and community members [13]. In Ethiopia peoples think that mental illness results from sprites and other evil forces and there are different institutions who deals with mentally ill individuals like in Coptic Church, there are monks and priests that are specialized in healing practices often using holy water sites [14]. In Ethiopia the prevalence of mental illness among holy water users and the reason why peoples prefer to use holy water is not known. Hence identifying mental illness among holy water users could show the real magnitude of the problem and associated factors for mental illness.

Objective: To assess the magnitude and associated factors of mental illness among holy water users at Entoto St. Mary church, Addis Ababa, Ethiopia, 2014.

\section{Methods}

\section{Study design and setting}

Institutional based cross sectional study was conducted at holy water of Entoto St. Mary church which established in 1878 by emperor Menilik $2^{\text {nd }}$ and impress Taytu as St. Mary church. The holy water gives services for more than ten thousand peoples per year. Mentally ill individuals go to the holy water either before they visit health institutions or after they get modern treatment. The reported case of "madness" is the common disorder which is cured.

\section{Sample size and sampling technique}

Sample size was determined by using Single population proportion formula. By taking proportion of mental illness $50 \%$, with $5 \%$ margin of error, $95 \% \mathrm{CI}$ and $10 \%$ non-response rate the total sample size was calculated to be 423 . Holy water users with communication problem during the time of data collection were excluded: The study participants were recruited from the registration book by using systematic random sampling.

\section{Data collection tool and procedures}

Data were collected by face-to-face interviews using structured questionnaire for socio demographic and substance related factors. The questionnaire was first prepared in English then translated to local language (Amharic) and back to English to maintain conceptual consistency. Brief Psychiatric Rating Scale (BPRS) was used to detect mental illness symptoms. The original Brief Psychiatric Rating Scale (BPRS) was first published in 1962 as a 16-item tool by Drs. John Overall and Donald Gorham [15]. It was initially devised as an instrument to assess the symptoms of schizophrenia on five subscales of thought disorder, withdrawal, anxiety/depression, hostility and activity [16]. Then it became expanded to 18 items and finally expanded as a 24 item having seven scale measurements ranging from "not present" to "extremely severe [17]. Even though it has seven scales; it can be compressed in to three point severity scales: lack of symptom (scored
1); sub-clinical symptom - medium severity (scored 2); pathological symptom - high severity (scored 3) for identifying the presence or absence of psychopathology depending on the suggestion of the authors. Items $1-14$ was rated on the basis of individuals self-report. Items 7, 12 and 13 are also rated on the basis of observed behavior. Items 15-24 are rated on the basis of observed behaviour and speech. It provides a standard basis for cross-cultural research in screening of psychiatric disorders [18]. It also used as a golden standard tool to adapt SRQ in Ethiopia [19]. A participant was considered as mentally ill if total score of BPRS-E is more than or equal to 31 .

\section{Data quality assurance, processing and analysis}

Data were collected by face to face interview technique and observation using structured and pretested questionnaire. The questionnaire was first prepared in English then translated to local language (Amharic) and back to English to maintain conceptual consistency. Four psychiatric nurses collected the data with close supervision. The filled questionnaires were checked for completeness and entered into EPI INFO version 3.5.1. Statistical software and then exported to SPSS version 20 for further analysis. Descriptive statistics was used to describe the study population in relation to relevant variables. Both bivariate and multivariate logistic regression models were used to identify associated factors. Odds Ratios and their $95 \%$ Confidence Intervals were computed and variables with $\mathrm{p}$ - value less than 0.05 were considered as significantly associated with the outcome variable. Ethical clearance was obtained from the Institutional review board of University of Gondar and Amanuel mental specialized hospital. A formal letter of cooperation was written to Entoto St Mary church. Verbal consent was obtained from each study participants

\section{Result and Discussions}

\section{Socio demographic characteristics}

A total of 416 participants were interviewed and observed with a response rate of $98.35 \%$. Among them 213(51.2\%) were females. Half of the participants were in age group of 26-40 with mean age of 33.77 ( \pm 13.37 ) and $95 \%$ of the respondents are orthodox in religion. From total participants $257(61.8 \%)$ of them were single, followed by $98(23.6 \%)$ married in marital status. Regarding educational status $137(32.9 \%)$ of the participants were in secondary school followed by $124(29.8 \%)$ primary school. Two hundred thirty four (56.3\%) of the participants are Amhara in ethnicity followed by $77(18.5 \%)$ Oromo and $84.1 \%$ of them live urban. Concerning the study subjects' occupational status $77.9 \%$ of them had a job (predominated by private employee $18.5 \%$ followed by $16.1 \%$ of government employee) and the remaining $22.1 \%$ are jobless. Their monthly income ranges from 50 to 36, 000 with median income of 775 birr (Table 1). Length of stay in the holy water ranges from one day to 45 days.

\section{Life time and current substance use}

Two hundred ninety three $(70.4 \%)$ of the study participants use at least one substance in their life time i.e. either alcohol, tobacco products, khat or cannabis and 115(27.6\%) of the respondents use more than one substance. concerning using substance in the last three months 192(46.2\%) of the participants use at least one substance (Table 2).

\section{Clinical characteristics of the participants}

Among total of 416 participants 77(18.5\%) of them had a known history of previous psychiatric illness but only $6(7.79 \%)$ of them are taking medication in the holy water. Forty three $(10.3 \%)$ of the 


\begin{tabular}{|c|c|c|}
\hline \multicolumn{2}{|c|}{ Variable } & Frequency (\%) \\
\hline \multirow{2}{*}{ Sex } & Male & $203(48.8)$ \\
\hline & Female & $213(51.2)$ \\
\hline \multirow{4}{*}{ Age } & $18-25$ & $117(28.1)$ \\
\hline & $26-40$ & $208(50.0)$ \\
\hline & $41-64$ & $82(19.7)$ \\
\hline & $65^{+}$ & $9(2.2)$ \\
\hline \multirow{4}{*}{ Religion } & Orthodox & $395(95.0)$ \\
\hline & Islam & $13(3.1)$ \\
\hline & Protestant & $4(1)$ \\
\hline & Catholic & $4(1)$ \\
\hline \multirow{4}{*}{ Marital status } & Single & $257(61.8)$ \\
\hline & Divorced & $40(9.6)$ \\
\hline & Widowed & $21(5.0)$ \\
\hline & Married & $98(23.6)$ \\
\hline \multirow{4}{*}{ Educational status } & Illiterate & $68(16.3)$ \\
\hline & Primary school & $124(29.8)$ \\
\hline & Secondary school & $137(32.9)$ \\
\hline & Diploma and above & $87(20.9)$ \\
\hline \multirow{5}{*}{ Ethnicity } & Amhara & $234(56.3)$ \\
\hline & Oromo & $77(18.5)$ \\
\hline & Tigre & $47(11.3)$ \\
\hline & Gurage & $40(9.6)$ \\
\hline & Others* & $18(4.3)$ \\
\hline \multirow{2}{*}{ Place of residence } & Urban & $350(84.1)$ \\
\hline & Rural & $66(15.9)$ \\
\hline \multirow{2}{*}{ Occupational status } & Jobless & $92(22.1)$ \\
\hline & Had a job & $324(77.9)$ \\
\hline
\end{tabular}

Table 1: Socio demographic characteristics of holy water users at Entoto St. Mary church, Addis Ababa, Ethiopia. NB: others* include Sidama, Silte, Wolita and Doreze.

\begin{tabular}{|c|c|c|c|}
\hline \multicolumn{2}{|l|}{ Variable } & Yes/no & Frequency (\%) \\
\hline \multirow{4}{*}{$\begin{array}{l}\text { Ever use of } \\
\text { substance }\end{array}$} & \multirow{2}{*}{$\begin{array}{l}\text { Use of single } \\
\text { substance }\end{array}$} & Yes & $293(70.4)$ \\
\hline & & No & $123(29.6)$ \\
\hline & \multirow{2}{*}{$\begin{array}{l}\text { Use of two or more } \\
\text { substances }\end{array}$} & Yes & $115(27.6)$ \\
\hline & & No & $305(72.4)$ \\
\hline \multirow{8}{*}{$\begin{array}{l}\text { Current use of } \\
\text { substance }\end{array}$} & \multirow{3}{*}{ Alcohol } & Never & $208(50.0)$ \\
\hline & & $\begin{array}{l}\text { Once/twice, monthly } \\
\text { or weekly }\end{array}$ & $152(36.5)$ \\
\hline & & Daily & $56(13.5)$ \\
\hline & \multirow{3}{*}{ Tobacco } & Never & $378(90.9)$ \\
\hline & & $\begin{array}{c}\text { Once/twice, monthly } \\
\text { or weekly }\end{array}$ & $15(3.6)$ \\
\hline & & Daily & $23(5.5)$ \\
\hline & \multirow{2}{*}{ Khat } & Never & $363(87.3)$ \\
\hline & & Daily & $53(12.7)$ \\
\hline
\end{tabular}

Table 2: Substance use among holy water users at Entoto St. Mary church, Addis Ababa, Ethiopia, 2014.NB: Never: not used in the last 3 months Once or twice: 1 to 2 times in the last 3 months. Monthly: 1 to 3 times in one month. Weekly: 1 to 4 times per week. Daily or almost daily: 5 to 7 days per week.

participants had family history of mental illness. Ninety four (22.6\%) of the study participants had a reported known medical condition. HIV/ AIDS, TB, Gastric abnormalities and kidney problems were among mentioned by participants (Table 3 ). All of the participants didn't have any advice or referral paper from holy water to psychiatric institutions.

\section{Magnitude of mental illness}

Presence of mental illness was assessed by interviewing and observing participants using Brief Psychiatric Rating Scale (BPRS). Out of the total study subjects 250(60.1\%) had BPRS score of $\geq 31$.
Hence, the prevalence of mental illness in the holy water was $60.1 \%$. Among study subjects who were diagnosed as mentally ill by BPRS 129 (51.6\%) were females and $133(53.2 \%)$ of them are in the age group of 26-40 years old followed by $72(28.8 \%)$ age group of $18-25$ years old. Regarding mental illness and marital status in the study area; 169 $(67.6 \%)$ of mentally ill study subjects were single followed by married $47(18.8 \%)$ and $77(30.8 \%)$ were in primary school educationally.

From mentally ill individuals 180 (72\%) were using at least one substance once in their life time and 91 (36.4) of were using more than one substance. only $20(8 \%)$ were using tobacco products in the last three months; 49 (19.6\%) were drinking alcohol daily and 88 (35.2\%) were occasional drinkers meanwhile 42 (16.8\%) were daily khat chewers. Among mentally ill individuals 68 (27.2\%) had previous history of mental illness; $36(14.45)$ of the study participants had family history of mental illness. 72 (28.8\%) of mentally ill study subjects had a known medical or surgical illness. The possible reason for such high prevalence of mental illness may be peoples prefer religious places over psychiatric institutions due to their thought about the cause of mental illness i.e. bad sprit, possession, super natural which result in seeking of religious help. The other reasons may be fear of stigma due to getting help from modern psychiatric facilities and believing mental illness is not treatable $[12,13]$.

\section{Factors associated with mental illness}

In Bi-variate analysis age, marital status, occupational status, ever use of more than one substance, current use of tobacco, current alcohol intake, current khat chewing, having previous psychiatric illness, family history of mental illness and having a diagnosed medical or surgical illness show $\mathrm{P}$ value $\leq 0.2$ and included in multiple logistic regration analysis. During multiple logistic regressions; being jobless $[\mathrm{AOR}=2.42,95 \% \mathrm{CI}(1.37,4.28)]$, ever use of more than one substance (i.e. alcohol, tobacco, khat and cannabis) $[\mathrm{AOR}=2.4,95 \% \mathrm{CI}(1.39$, $4.17)]$, current daily drinking of alcohol $[\mathrm{AOR}=5.08,95 \% \mathrm{CI}(2.08$, 12.2)], having previous history of mental illness $[\mathrm{AOR}=5.82,95 \% \mathrm{CI}$ $(2.732,12.378)]$ and having a diagnosed medical or surgical problem $[\mathrm{AOR}=2.46,95 \% \mathrm{CI}(1.39,4.34)]$ were significantly associated (Table 4). The odds of having mental illness for jobless holy water users were 2.42 times more when compared with holy water users with job. The possible explanation for this may be mental illness may result from stress due to inability to full fill basic needs, risk for substance use, nutritional imbalance, social and familial difficulties and loss of hope. Holy water users who have history of using more than one substance had 2.4 more odds for mental illness when compared with users who don't have substance use history. This may be due to physiological effect of substance, economical effect and social functioning impairment this will even more when an individual is using more than one substance which also may be sign of dependency. The odds of having mental health for daily alcohol drinker holy water users were 5.08 times than the odds of individuals who don't drink alcohol. Individuals who consume alcohol daily have difficulty of living, doing and functioning

\begin{tabular}{|c|c|c|}
\hline \multicolumn{2}{|c|}{ Variables } & Frequency (\%) \\
\hline \multirow{2}{*}{ Previous history of psychiatric illness } & Yes & $77(18.5)$ \\
\cline { 2 - 3 } & No & $339(81.5)$ \\
\hline \multirow{2}{*}{ Family history of mental illness } & Yes & $43(10.3)$ \\
\cline { 2 - 3 } & No & $373(89.7)$ \\
\hline \multirow{2}{*}{ Known medical condition } & Yes & $94(22.6)$ \\
\cline { 2 - 3 } & No & $322(77.4)$ \\
\hline
\end{tabular}

Table 3: clinical characteristics of study participants at Entoto St. Mary church holy water Addis Ababa, Ethiopia. 
Citation: Fekadu W, Mulat H, Haile K, Mehretie Y, Mekonen T (2015) Magnitude of Mental Illness and Associated Factors among Holy Water Users at Entoto St. Mary Church, Addis Ababa, Ethiopia, 2014. J Psychiatry 18: 285 doi: 10.4172/2378-5756.1000285

Page 4 of 5

\begin{tabular}{|c|c|c|c|c|c|}
\hline \multirow{2}{*}{\multicolumn{2}{|c|}{ Variables }} & \multicolumn{2}{|c|}{ Mental illness } & \multirow{2}{*}{ COR(95\% Cl) } & \multirow{2}{*}{ AOR(95\% Cl) } \\
\hline & & Yes & No & & \\
\hline \multirow{4}{*}{ Age } & $18-25$ & 72 & 45 & $3.2(.76,13.44)$ & $3.32(.68,16.18)$ \\
\hline & $26-40$ & 133 & 75 & $3.55(.86,14.6)$ & $3.06(.65,14.52)$ \\
\hline & $41-64$ & 42 & 43 & $2.1(.49,8.97)$ & $2.01(.41,9.92)$ \\
\hline & $65^{+}$ & 3 & 6 & 1 & 1 \\
\hline \multirow{4}{*}{ Marital status } & Single & 169 & 88 & $2.08(1.23,3.34)$ & $1.4(.79,2.5)$ \\
\hline & Divorced & 25 & 15 & $1.81(.85,3.84)$ & $1.71(.74,3.91)$ \\
\hline & Widowed & 9 & 12 & $.81(.31,2.1)$ & $1.04(.32,3.39)$ \\
\hline & Married & 47 & 51 & 1 & 1 \\
\hline \multirow{2}{*}{ Occupational status } & Have job & 181 & 143 & 1 & 1 \\
\hline & Jobless & 69 & 23 & $2.37(1.4,3.99)$ & $2.42(1.37,4.28)^{\star}$ \\
\hline \multirow{2}{*}{ ever use of more than one substance } & No & 159 & 142 & 1 & 1 \\
\hline & Yes & 91 & 24 & $3.39(2.05,5.6)$ & $2.4(1.39,4.17)^{*}$ \\
\hline \multirow{2}{*}{ Current use of tobacco } & Never & 219 & 159 & 1 & 1 \\
\hline & Daily & 20 & 3 & $4.84(1.4,16.57)$ & $.71(.13,3.79)$ \\
\hline \multirow{3}{*}{ Current alcohol use } & Never & 113 & 95 & 1 & 1 \\
\hline & $\begin{array}{c}\text { Once or twice, monthly, } \\
\text { weekly }\end{array}$ & 88 & 64 & $1.16(.76,1.76)$ & $1.18(.74,1.87)$ \\
\hline & Daily & 49 & 7 & $5.89(2.55,13.6)$ & $5.04(2.08,12.2)^{\star}$ \\
\hline \multirow[b]{2}{*}{ Current khat chew } & Never & 208 & 155 & 1 & 1 \\
\hline & Daily & 42 & 11 & $2.85(1.42,5.71)$ & $.51(.17,1.51)$ \\
\hline \multirow{2}{*}{ Previous history of mental illness } & No & 182 & 157 & 1 & 1 \\
\hline & Yes & 68 & 9 & $6.52(3.15,13.49)$ & $5.82(2.73,12.38)^{+*}$ \\
\hline \multirow{2}{*}{ Family history of mental illness } & No & 214 & 159 & 1 & 1 \\
\hline & Yes & 36 & 7 & $3.82(1.66,8.81)$ & $1.42(.543 .71)$ \\
\hline \multirow{2}{*}{ Known medical illness } & No & 178 & 144 & 1 & 1 \\
\hline & Yes & 72 & 22 & $2.65(1.57,4.48)$ & $2.46(1.39,4.34)^{\star}$ \\
\hline
\end{tabular}

Table 4: Logistic regression of mental illness among holy water users at Entoto St. Mary church, Ethiopia. "p-value less than 0.01 , " $p$-value less than 0.001.

without drinking. Even though study participants may drink different types of alcohol; having different strength or alcohol level, amount; it shows these individuals are dependent on alcohol to function which also have structural, familial, economical and social consequences which may also result in mental illness. The odds of mental illness for holy water users having previous history of mental illness were 5.82 times more than who don't have previous history of mental illness. Having previous history of psychiatric may contribute for current illness due to not getting psychiatric treatment, poor medication adherence, continuous stressor from previous illness, unremitted previous psychiatric symptoms, stigma due to the previous illness, problem of social relationship and poor functioning.

The odds of mental illness for holy water users who had known diagnosed medical or surgical illness were 2.46 more than holy water users who didn't have known medical or surgical illness. Medical or surgical problems may result in mental illness due to stress, physiological or anatomical effect, immunological problem, effect of medication, medication interaction and some illnesses like HIV result in stigma which may either result or exacerbate mental illness.

\section{Conclusion and Recommendations}

Prevalence of mental illness was found high among holy water users. Being jobless, ever use of more than one substance, current daily drinking of alcohol, having previous history of mental illness and having a known diagnosed medical or surgical problem were significantly associated. So it needs to give attention to develop reference link between psychiatric institutions and religious places, communities' awareness about the cause, treatment options of mental illness must be enhanced.

\section{Acknowledgment}

The research was funded by Amanuel mental specialized hospital.

\section{References}

1. American Psychiatric Association (2000) Diagnostic and statistical manual of mental disorders: DSM-IV-TR ${ }^{\circledR}$ : American Psychiatric Pub.

2. WHO (2008) the bare fact. world health report.

3. Moffitt AC, Taylor A, Kokaua J, Milne BJ, Polanczyk G, et al. (2010) How common are common mental disorders? Evidence that Lifetime prevalence rates are doubled by prospective versus retrospective ascertainment. Psychol Med 40: 899-909.

4. Kessler R, Angermeyer M, Anthony JC, de Graaf R, Demyttenaere K, et al (2007) Lifetime prevalence and age-of-onset distributions of mental disorders in the World Health Organization's World Mental Health Survey Initiative. World Psychiatr 6: 168.

5. Consortium S (2004) Prevalence, severity, and unmet need for treatment of mental disorders in the World Health Organization World Mental Health Surveys. JAMA: the journal of the American Medical Association 291: 2581-90.

6. Organisation for economic co-operation, and development (2008) Mental Health in OECD Countries. Policy briefs.

7. Kessler RC, Berglund P, Demler O, Jin R, Merikangas KR, et al. (2005) Lifetime prevalence and age-of-onset distributions of DSM-IV disorders in the National Comorbidity Survey Replication. Archives of general psychiatry 62: 593-602.

8. Alegría M, Mulvaney-Day N, Torres M, Polo A, Cao Z, et al. (2007) Prevalence of psychiatric disorders across Latino subgroups in the United States. American Journal of Public Health 97: 68.

9. Sorsdahl K, Stein DJ, Grimsrud A, Seedat S, Flisher AJ, et al. (2009) Traditional healers in the treatment of common mental disorders in south africa. The Journal of nervous and mental disease 197: 434-41.

10. Robertson J (2007) Common mental health problems in historically disadvantagedurban and rural communities in South Africa: prevalence and risk factors. Social Psychiatry and Psychiatric Epidemiology. 
Citation: Fekadu W, Mulat H, Haile K, Mehretie Y, Mekonen T (2015) Magnitude of Mental Illness and Associated Factors among Holy Water Users at Entoto St. Mary Church, Addis Ababa, Ethiopia, 2014. J Psychiatry 18: 285 doi: 10.4172/2378-5756.1000285

Page 5 of 5

11. Read D (2012) mental health research in ghana: a literature review.

12. Nsereko J, Kizza D, Kigozi F, Ssebunnya J, Ndyanabangi S, et al. (2011) Stakeholder's perceptions of help-seeking behaviour among people with mental health problems in Uganda. International Journal of Mental Health Systems. 5: 5 .

13. Peter Ventevogel MJ, Ria Reis, Joop DJ (2013) Madness or sadness? Local concepts of mental illness in four conflict-affected African communities. Conflict and Health 7.

14. Jacobsson L (2002) Traditional treatment of mental and psychosomatic disorders in Ethiopia. International Congress Series. 1241: 265- 9.

15. Donald O (1962) The Brief Psychiatric Rating Scale. Psychological Reports. Psychological Reports 10: 799-812.
16. Deady M (2009) A Review of Screening, Assessment and Outcome Measures for Drug and Alcohol Settings. Drug and Alcohol and Mental Health Information Management Project.

17. Lukoff D, Liberman RF, Nuechterlein KH (1986) Symptom monitoring in the rehabilitation of schizophrenic patients. Schizophrenic Bulletin 12: 578-602.

18. Hedlund JL, Vieweg (1980) The Brief Psychiatric Rating Scale (BPRS): A comprehensive review. Journal of Operational Psychiatry 11: 48-63.

19. Rafael Y, Fikre W, Robert G (2008) Adapting the SRQ for Ethiopian Populations: A Culturally-Sensitive Psychiatric Screening Instrument. Trans cultural Psychiatry 45. 